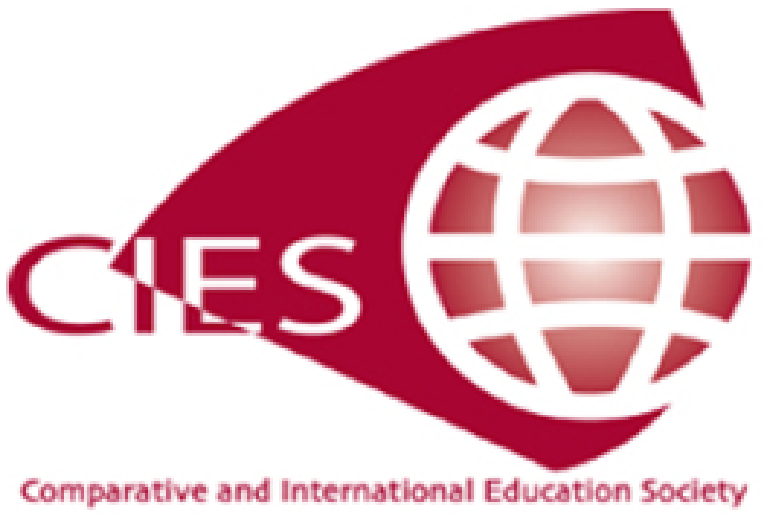

Mathematics Teachers' Didactic Strategies: Examining the Comparative Potential of Low Inference Generic Descriptors

Author(s): Paul Andrews

Source: Comparative Education Review, Vol. 53, No. 4 (November 2009), pp. 559-581

Published by: The University of Chicago Press on behalf of the Comparative and International Education Society

Stable URL: http://www.jstor.org/stable/10.1086/603583

Accessed: $22 / 08 / 2013$ 03:50

Your use of the JSTOR archive indicates your acceptance of the Terms \& Conditions of Use, available at http://www.jstor.org/page/info/about/policies/terms.jsp

JSTOR is a not-for-profit service that helps scholars, researchers, and students discover, use, and build upon a wide range of content in a trusted digital archive. We use information technology and tools to increase productivity and facilitate new forms of scholarship. For more information about JSTOR, please contact support@jstor.org.

The University of Chicago Press and Comparative and International Education Society are collaborating with JSTOR to digitize, preserve and extend access to Comparative Education Review. 


\title{
Mathematics Teachers' Didactic Strategies: Examining the Comparative Potential of Low Inference Generic Descriptors
}

\author{
PAUL ANDREWS
}

\section{Introduction}

Much recent comparative mathematics education research, drawing on a belief that teachers in one country behave in ways that identify them more closely with colleagues from their own country than elsewhere (Schmidt et al. 1996), has focused on explicating the national mathematics teaching script. The justification generally is as follows: "Teaching and learning are cultural activities [that] . . . often have a routineness about them that ensures a degree of consistency and predictability. Lessons are the daily routine of teaching and learning and are often organized in a certain way that is commonly accepted in each culture" (Kawanaka et al. 1999, 91). These didactic routines have been variously described as the traditions of classroom mathematics (Cobb et al. 1992), cultural scripts (Stigler and Hiebert 1999), lesson signatures (Hiebert et al. 2003), or the characteristic pedagogical flows of a lesson (Schmidt et al. 1996). Advocates locate their explanations in the belief that cultures "shape the classroom processes and teaching practices within countries, as well as how students, parents and teachers perceive them" (Knipping 2003, 282), to the extent that many of the processes of teaching are so "deep in the background of the schooling process . . . so taken-for-granted . . . as to be beneath mention" (Hufton and Elliott 2000, 117). The quality of the script's warrant is, however, dependent on how researchers conceptualize classroom activity. In this article, therefore, we offer a particular perspective on this process.

An increasingly common approach to comparative education research, particularly with respect to mathematics education, has been the exploitation of video technology, not least because the use of video cameras offers several advantages over traditional methods such as direct observation (Stigler et al. 1999; Hiebert et al. 2003). It is important to acknowledge, however, that

The Mathematics Education Traditions of Europe (METE) project team gratefully acknowledges the financial support of the European Union, Socrates Action 6.1 program, project code 2002-5048. The METE project team included Erik De Corte, Fien Depaepe, Peter Op't Eynde, and Lieven Verschaffel (the Catholic University of Leuven); Paul Andrews (Cambridge University); Gillian Hatch (Manchester Metropolitan University); Judy Sayers (Northampton University); George Malaty and Tuomas Sorvali (University of Joensuu); Kati Fried, Sári Pálfalvi, Éva Szeredi, and Judit Török (Eötvös Loránd University); and José Carrillo, Nuria Climent, and Cinta Muñoz (University of Huelva).

Electronically published June 18, 2009

Comparative Education Review, vol. 53, no. 4.

(C) 2009 by the Comparative and International Education Society. All rights reserved. $0010-4086 / 2009 / 5304-0002 \$ 10.00$ 
video technology is not a panacea and that no recording will capture all classroom discourse (Ulewicz and Beatty 2001). In this article we present, from the perspective of warranting its methodological contribution to comparative mathematics education research, exemplary findings from a smallscale video study undertaken in five European countries. In so doing we show how generic codes applied to generic episodes facilitate simple yet detailed analyses with the potential not only for highlighting important similarities and differences in the ways in which teachers present mathematics in different countries but also for making an important contribution to the debate on the national mathematics script. Details of the project are presented below, informed by the methods and analyses of two of the better known videobased comparative studies of mathematics education: the Third International Mathematics and Science Study (TIMSS) video study (TVS; Stigler et al. 1999), its repeat (TVS-R; Hiebert et al. 2003), and the Learner's Perspective Study (LPS; Clarke, Emanuelsson, et al. 2006; Clarke, Keitel, et al. 2006). ${ }^{1}$ All three studies focused on students in grade 8 and present, in their very differing emphases and methodologies, differently framed and reported outcomes. Importantly, by way of facilitating our work, these studies provide extremely helpful insights into the ways in which video technology can be purposely exploited in the examination of teachers' approaches to their work.

\section{The METE Study}

The broad aim of the European Union-funded METE project was to examine how teachers conceptualize and present mathematics to students age 10-14 in Flanders, England, Finland, Hungary, and Spain. ${ }^{2}$ These countries reflect well not only the cultural diversity of Europe but also the substantial variation in achievement on tests of routine mathematics competence, such as TIMSS (Beaton et al. 1996; Mullis et al. 2000, 2004, 2008), and mathematical applicability, such as the Program for International Student Assessment (OECD 2001, 2004). A particular aim was to exploit the potential of videotape, and this goal was realized by recording, in each country, four or five successive lessons on topics agreed by project colleagues as representative of not only their countries' curricula but also the transition of school mathematics from concrete and inductive to abstract and deductive. Our

\footnotetext{
${ }^{1}$ The TVS analyzed single lessons taught by representative samples of teachers in Germany, Japan, and the United States. The TVS-R focused on Australia, the Czech Republic, the Hong Kong Special Administrative Region, the Netherlands, Switzerland, and the United States. The LPS collected data from three sequences of 10 lessons taught by teachers defined locally as effective in Australia, China, the Czech Republic, Germany, Israel, Japan, Korea, the Philippines, Singapore, South Africa, Sweden, and the United States.

${ }^{2}$ To simplify the discussion, we regard Flanders, one of the two autonomous provinces of Belgium, as a country. Although data were collected in Finland and have been analyzed qualitatively, ill health of the Finnish coordinator prevented their being coded for quantitative analysis, and so data from only four countries are reported here.
} 
justification for this approach, despite James Stigler et al.'s (1999, 7) assertion that "across cultures, teachers may define topics so differently that the resulting samples become less rather than more comparable," lay in the belief that understanding how mathematics is conceptualized, by both systems and teachers, would be facilitated by an examination of similar topics taught to students of similar ages. Furthermore, the project team's decision to examine sequences, which acknowledged the loss of generality embedded in the TVS design, made showpiece lessons essentially impossible.

The four topics were percentages in grades 5 or 6 , polygons in grades 5 or 6 , polygons again in grades 7 or 8 , and linear equations in grades 7 or 8. ${ }^{3}$ The teachers involved, four per country, were selected against local criteria of effectiveness in the manner of the LPS (Clarke 2006), thus minimizing the possibility of selection bias. Also, whereas LPS as well as TVS and TVS$\mathrm{R}$ attended to a single age group, the METE team studied two age groups, upper primary and lower secondary, to allow for the examination of crossphase differences in teachers' mathematics-related didactic behaviors.

As indicated, data collection drew extensively on videotape. Unfortunately, funds did not allow for a week-long "familiarization period" (Clarke 2006, 20), although, as we show, strategies were adopted to minimize the intrusive effect of both camera and operator. Like the first TVS (Stigler et al. 1999), the METE team used a single camera. Unlike the TVS, attention was focused on all utterances made by the teacher and as much board work as possible. Constraining the process in this manner minimized videographer decisions as to what should be the focus of attention (Ulewicz and Beatty 2001). In all cases, a tripod-mounted camera was placed near the rear of the room. Teachers wore radio microphones, while strategically placed telescopic microphones captured as much student talk as possible. Since attention was on the ways in which teachers structured opportunities for learning-as reflected in their observed conceptualization and presentation of mathematics-the integrity of data collection was not greatly compromised through lost student talk. After filming, each digital tape was compressed and transferred to CD for coding, copying, and distribution.

\section{The Generic Episode}

Initially, we planned to focus on common lesson phases, but greater than expected cross-national variation prevented this approach. Subsequently, we defined the unit of analysis in terms of the generic episode, in which an episode was defined as that part of a lesson in which the teacher's observable didactic intention remained constant. In this manner, a section of a lesson

\footnotetext{
${ }^{3}$ Percentages were chosen as an example of applied arithmetic and as an opportunity to examine how teachers link their teaching to a world outside mathematics. Polygons were chosen as a typical geometrical topic of project curricula with repetition reflecting an attempt to facilitate cross-phase comparison. Linear equations represented an iconic topic in the transition from arithmetic to symbolic algebra.
} 
in which a teacher models an algorithm to the whole class, followed by an exercise in which students work independently from a text, would be construed as two episodes. The observed intention of the first phase would be an explicit act of teaching, while the observed intention of the second would be consolidation and practice.

In some respects the METE generic episode resembled the activity segment of the TVS, which is that part "of the lesson that serves some specific pedagogical function" (Stigler et al. 1999, 79). Importantly, as we show below, episode, or segment, boundaries are generally straightforwardly defined as the "end of one segment by definition marks the beginning of the following" (Knoll and Stigler 1999, 730). The episode, as defined by the METE team, differs from the LPS's lesson event (Clarke, Mesiti, et al. 2006), which pertains to an activity, frequently tied to a particular lesson phase, characteristic of a particular country. Moreover, whereas the postlesson interviews of the LPS allowed for lessons to be parsed according to articulated teacher decisions, the nature of the METE data necessitated episode entry and exit points being determined by observable criteria. After some discussion, during which whole-class teaching and seat work were revisited as possible defining contenders, we decided to use a shift in the observed didactic intention as a generic criterion. In this way, any change of intention would, implicitly, reflect teacher decision making.

\section{Developing the Coding Schedule}

The coding schedule was developed during the first year of the project, and full details of this process can be found in Paul Andrews's work (2007b), although a summary is presented here. The original intention was to exploit existing frameworks, starting with the five strands of mathematical proficiency (Kilpatrick et al. 2001) and the distinction between conceptual knowledge and procedural knowledge (Hiebert 1986). Since we came to realize that such supposedly "universal" concepts frequently had contextually located meanings, however, we initiated a bottom-up process of observation, discussion, and code development. This process lasted almost a year, during which 1 week of observations was undertaken in each country, with one lesson being observed each morning by at least one member of each project team. Each observation was supported by a home colleague offering a sotto voce translation (Alexander 1999) and the videotaping of the lesson to facilitate discussion the same afternoon. Discussions tended to follow the same format. The videotape was played as many times as was necessary to ensure colleagues were confident they had a clear sense as to the structure of the lesson and its activities before discussion and schedule development began.

Early in the first observation week, almost four pages of descriptors, loosely structured by team members' perceptions of typical lesson phases, had emerged. By the end of the week, we concluded that highly specified 
TABLE 1

Working Definitions of the 10 Generic Didactic Strategies Developed during the First Year of the Project and Exploited in the Analysis of Videotaped Lessons

\begin{tabular}{ll}
\hline Code & Definition \\
\hline $\begin{array}{c}\text { Activating prior } \\
\text { knowledge }\end{array}$ & $\begin{array}{c}\text { The teacher focuses students' attention on mathematical ideas covered earlier in } \\
\text { their careers as preparation for activities to follow. Activating, in this sense, is } \\
\text { not construed as a review of the previous lesson but may frequently concern the } \\
\text { making of links between mathematical entities. }\end{array}$ \\
$\begin{array}{c}\text { Exercising prior } \\
\text { knowledge }\end{array}$ & $\begin{array}{c}\text { The teacher focuses learners' attention on mathematical ideas covered earlier in } \\
\text { their careers in the form of a period of revision unrelated to any activities that } \\
\text { follow. As with activating, exercising of prior knowledge is not construed as a } \\
\text { review of the previous lesson. }\end{array}$ \\
Explaining & $\begin{array}{c}\text { The teacher explains an idea or solution. Typically this may include demonstra- } \\
\text { tion, telling, or the modeling of procedures or problem-solving strategies. In }\end{array}$ \\
such instances the teacher is the informer, with little or no student input. \\
The teacher engages learners in a process of public sharing of ideas, solutions, or \\
answers. Typically, the emphasis would be on students to lead the discourse, \\
with teachers acting in supportive roles. \\
The teacher engages learners in a student-controlled activity from which new \\
mathematical ideas are intended to emerge. Typically this would be an investiga- \\
tion or a sequence of structured problems, but in all cases students are ex- \\
pected to make independent discoveries.
\end{tabular}

or too-broad categorizations would be unlikely to yield data helpful for understanding how teachers, in five countries, conceptualize and present mathematics. Consequently, a decision was made to focus on the development of a relatively small number of simple-to-operationalize descriptors linked to generic didactic activities and learning objectives. Eventually, we created a framework comprising three sections: seven observable learning outcomes, four task descriptors, and 10 didactic strategies. All colleagues later involved in the application of the codes were involved in this cyclic process of code development. Moreover, observing lessons as they unfolded facilitated colleagues' understanding of the contexts in which they occurred. This article, for reasons of brevity, focuses solely on an analysis of teachers' observable didactic strategies, working definitions of which can be seen in table 1 .

Each episode was coded by members of its home team. There was no limit to the number of codes that could be applied; the only criterion was the observed presence of a didactic strategy. Consequently, the majority of episodes were multiply coded. No frequency count was made of the occurrences of a strategy within an episode, however. It was either present or not. 
Of course, the 10 didactic strategies on which this article is based are clearly not exhaustive, and many could be construed as comprising subcategories. By way of illustration, and because space prevents a discussion of all 10 strategies, we discuss how explaining could be construed as comprising several subcategories, all of which would fall within our definition, whereby the teacher informs but invites little or no student input.

First, though, we consider how the literature construes teacher explanation as a didactic device. In their most general sense, explanations, which have been described as "ubiquitous tools . . . to communicate key concepts, principles, and relationships" (Roscoe and Chi 2008, 321), should be relevant, coherent, complete, and accurate (King 1994). When effective, they draw on students' prior knowledge and exploit visual or concrete representations to link abstract and concrete models (Leinhardt and Steele 2005) and constitute not only "depth of content knowledge" but also "present content knowledge in a pedagogically meaningful way" (Inoue 2009, 48). However, relatively little research has addressed how explanation achieves these goals or, for example, the extent to which it incorporates other didactic strategies. An exception can be found in Gaea Leinhardt's (2001) four classifications: common, disciplinary, self, and instructional. Common explanations are responses to direct, socially located questions and conform to the polite norms of social discourse. Disciplinary explanations are domain specific and conform to the expectations, including, for example, epistemological norms, of the relevant discourse. Self-explanations are personal mechanisms for establishing meaning or developing understanding - my own redrafting of Leinhardt's categories is a form of self-explanation. Finally, instructional explanations are intended to teach some aspect of a particular subject matter to others. They are "jointly built through a coherent discourse surrounding a task or text that involves the whole class and the teacher working together" (Leinhardt 2001, 340).

Not all authors construe explanation as incorporating discussion, however. Hilda Borko and Carol Livingston (1989), for example, present explanation and discussion as distinct forms of instructional activity. The role of questioning within explanation also seems ambiguous. Brent Davis and Elaine Simmt (2006), in discussing the role of explanation as a means by which distributed prior knowledge can be made collective, tacitly incorporate not only discussion but questioning as elements of explanation. Borko $(2004,8)$, however, discusses questions and explanations as "specific instructional features," implying a distinction. Julia Aguirre and Natasha Speer (2000) have summarized teachers' accounts of explanation as, essentially, the presentation of definitive mathematical knowledge to passive students. Despite this ambiguity, there is evidence that poor subject matter knowledge frequently leads to procedurally focused explanations presented to passive audiences; highlevel subject knowledge facilitates more balanced outcomes and includes 
elements of discussion and questioning. Interestingly, Susan Stodolsky's (1988) notion of recitation, whereby the teacher explains material, invites students to respond to, essentially, closed questions, and explains (models) solutions to particular problems to guide practice, seems to fall between these two perspectives.

The METE team's perspective on explanation is eclectic but, as is discussed below, deliberately so. It acknowledges several possibilities, many of which resonate with the various perspectives above. For example:

- The teacher explains (presents) instructions.

- The teacher explains (demonstrates) how to complete routine tasks.

- The teacher explains (describes) new concepts.

- The teacher explains (models) how to solve nonroutine or unfamiliar problems.

- The teacher explains (derives) links between the current topic and others covered earlier.

Explaining construed in this manner represents a range of possible interpretations but clearly satisfies the criterion of being both generic and, based on the evidence presented below, simple to operationalize. Our conception of explaining may, however, be susceptible to charges of being too broad and inclusive to be useful. The project team's response, based on discussions over several months, is that that didactic strategy with which explaining is juxtaposed facilitates a warranted and more sophisticated interpretation of teachers' actions to be presented than when it is observed in isolation. For example, a random selection of episodes coded for both explaining and coaching showed that explaining always fell into the second category above. Thus, the juxtaposition of explaining and coaching alludes to an observed emphasis on procedural skills. Alternatively, when explaining was observed in episodes in which questioning was exploited, it tended to take one of the latter three forms above. Moreover, if an episode coded for both explaining and questioning incorporated activating, then it was linked either to nonroutine problems or links between topics. Thus, explaining, when juxtaposed with questioning, points toward conceptual rather than procedural emphases that, when further aligned with activating, allude to higher-order outcomes concerning the application of conceptual knowledge as manifested in either nonroutine problems or the structural properties of mathematics. In sum, the team believes that the codes' interactions facilitate an analysis more sophisticated than just the sum of the parts.

\section{Intercoder Reliability}

Where English was not the mother tongue, subtitles were created for the first two lessons of each sequence, enabling the English team to recode these particular lessons and establish intercoder reliability. The METE team used the Cohen kappa coefficient, which accounts for agreements due to chance. 
ANDREWS

TABLE 2

Summary Lesson Statistics

\begin{tabular}{|c|c|c|c|c|c|}
\hline & Flanders & England & Hungary & Spain & All \\
\hline Total lessons & 20 & 15 & 18 & 16 & 69 \\
\hline Mean lesson length & 50.1 & 53.1 & 45.9 & 58.2 & 51.5 \\
\hline Total episodes & 111 & 103 & 78 & 75 & 367 \\
\hline Total didactic codes & 299 & 237 & 320 & 264 & 1,120 \\
\hline Codes per episode & $2.7^{1}$ & $2.3^{2}$ & $4.1^{3}$ & $3.5^{4}$ & 3.05 \\
\hline Episodes per lesson & 5.6 & $6.9^{5}$ & $4.3^{6}$ & 4.7 & 5.3 \\
\hline Mean episode duration & 8.9 & $7.7^{7}$ & 10.4 & $12.5^{8}$ & 9.6 \\
\hline Standard deviation & 6.5 & 5.0 & 6.3 & 8.0 & 6.6 \\
\hline Superscript & $z$ & $P$ & Superscript & $z$ & $P$ \\
\hline 1 & 3.320 & $<10^{-3}$ & 5 & 9.271 & $<10^{-21}$ \\
\hline 2 & 7.071 & $<10^{-11}$ & 6 & 8.447 & $<10^{-16}$ \\
\hline 3 & 7.583 & $<10^{-13}$ & 7 & 3.539 & $<10^{-3}$ \\
\hline 4 & 3.968 & $<10^{-4}$ & 8 & 3.776 & $<10^{-3}$ \\
\hline
\end{tabular}

NoTE. - Various summary statistics for the lessons, episodes, and didactic codes observed in each country, including mean episode duration in minutes and its respective standard deviation. Superscripts refer to significant project-level differences, as identified by Mann-Whitney $U$-tests, comparing the figures for one country with those derived from all others.

Assuming a threshold of 0.75 , acceptable levels of intercoder reliability were found between the coders of England and Flanders $(\kappa=0.877)$, England and Hungary $(\kappa=0.875)$, and England and Spain $(\kappa=0.793)$.

\section{Results}

In the following discussion, we present an exemplary analysis of project data showing how the METE project's inductively derived generic codes, when applied to generic episodes, facilitate meaningful comparisons at several levels. Due to considerations of space, however, we focus on issues of validation and methodological contribution rather than a presentation of the complete analyses. To accomplish this task, we examine in depth the manifestation of explaining and its interactions with other observable strategies.

First, the figures in table 2 show that the number of codes per episode per country differed significantly, with both Flemish (2.7) and English (2.3) having significantly fewer and Hungarian (4.1) and Spanish (3.5) having significantly more codes per episode. The mean number of episodes per lesson in England (6.9) and Hungary (4.3) were significantly higher and lower, respectively, than the project mean of 5.3 episodes in all countries combined. Interestingly, when the product of codes per episode and episode per lesson is calculated, we can see that the number of codes per lesson is more or less constant at around 16 per country. It can also be seen that the mean English episode length, 7.7 min., and the mean Spanish, 12.5 min., were significantly shorter and longer, respectively, than the project mean of 9.6 min. 
In the following section we compare teachers' didactic strategies at both the project level (comparing the data from one country with those from all others) and the pair-wise level (comparing the data from one country with those from another). ${ }^{4}$ The number and proportion of episodes coded for each strategy in each country's lessons can be seen in table 3 . The figures show that teachers, irrespective of location, explain regularly. Indeed, this strategy was the only one that initial ANOVAs had not highlighted as influenced by nationality. As shown below, however, the manifestation of explaining varied according to the strategies observed contemporaneously. Other commonly observed strategies included sharing and coaching, although significant inter-international variation can be seen.

At the project level, highlighted by superscripts in table 3, there were significantly smaller proportions of coaching and motivating in the Flemish episodes than elsewhere. English episodes presented a higher proportion of exercising of prior knowledge and smaller proportions of activating, motivating, and questioning. Hungarian episodes comprised higher proportions of activating, sharing, assessing, motivating, and questioning and lower proportions of exploring and differentiating than elsewhere. Spanish episodes exhibited higher proportions of coaching, motivating, and questioning and a lower proportion of assessing than elsewhere. Importantly, exercising, exploring, and differentiating, despite small significant differences, were so infrequently observed that we decided to exclude them from the analysis.

At the pair-wise level, highlighted by subscripts in table 3, Flemish episodes comprised a significantly higher proportion of questioning than the English but a lower proportion than either the Hungarian or the Spanish. Also, Flemish episodes included significantly smaller proportions of sharing, assessing, and motivating than did episodes in Hungary as well as a significantly higher proportion of assessing but smaller proportions of coaching and motivating than in Spain. English episodes comprised a significantly smaller proportion of questioning than did episodes in Flanders, Hungary, or Spain. Furthermore, English episodes included smaller proportions of activating, sharing, assessing, and motivating than did episodes in Hungary and a significantly higher proportion of assessing but smaller proportions of

\footnotetext{
${ }^{4}$ The nature of the latter required consideration of the threshold probabilities for rejecting null hypotheses, although the Fisher least significant difference procedure requires no change provided an analysis of variance proves significant. Our view, despite the semblance of generality implicit in almost four hundred episodes, was that the small number of lessons may have inadvertently contributed to type I errors. Alternatively, the Bonferroni correction, which expects no initial ANOVA, requires the probability threshold to be divided by the number of comparisons. In our case, pair-wise comparisons across four countries would require six comparisons with a probability threshold of $0.05 / 6=0.0083$. The Bonferroni correction tends, however, to increase the likelihood of type II errors. Therefore, in what we believe is a novel approach, we compromised. Where analyses of variance were significant, we adopted a probability threshold of twice the Bonferroni value, 0.0167. This strategy insured against type I errors caused by a small sample and type II errors due to overcaution.
} 
ANDREWS

TABLE 3

Summary Code Statistics

\begin{tabular}{|c|c|c|c|c|c|c|c|c|c|c|}
\hline & \multicolumn{2}{|c|}{ Flanders } & \multicolumn{2}{|c|}{ England } & \multicolumn{2}{|c|}{ Hungary } & \multicolumn{2}{|c|}{ Spain } & \multicolumn{2}{|c|}{ All } \\
\hline & Count & $\%$ & Count & $\%$ & Count & $\%$ & Count & $\%$ & Count & $\%$ \\
\hline Activating & 26 & 23.4 & $12_{\mathrm{J}}^{3}$ & 11.7 & $27_{\mathrm{J}, \mathrm{T}}^{7}$ & 34.6 & $10_{\mathrm{T}}$ & 13.3 & 75 & 20.4 \\
\hline Exercising & 3 & 2.7 & $8^{4}$ & 7.8 & 4 & 5.1 & $0^{14}$ & .0 & 15 & 4.1 \\
\hline Explaining & 58 & 52.3 & 54 & 52.4 & 46 & 59.0 & 48 & 64.0 & 206 & 56.1 \\
\hline Sharing & $68_{\mathrm{B}}$ & 61.3 & $62_{\mathrm{K}}$ & 60.2 & $76_{\mathrm{B}, \mathrm{K}, \mathrm{U}}^{8}$ & 97.4 & $46_{\mathrm{U}}$ & 61.3 & 252 & 68.7 \\
\hline Exploring & 7 & 6.3 & 4 & 3.9 & $0^{9}$ & .0 & 4 & 5.3 & 15 & 4.1 \\
\hline Coaching & $43_{\mathrm{F}}^{1}$ & 38.7 & $56_{\mathrm{P}}$ & 54.4 & $35_{\mathrm{V}}$ & 44.9 & $57_{\mathrm{F}, \mathrm{P}, \mathrm{V}}^{15}$ & 76.0 & 191 & 52.0 \\
\hline Assessing & $22_{\mathrm{C}, \mathrm{G}}$ & 19.8 & $14_{\mathrm{L}, \mathrm{Q}}$ & 13.6 & $28_{\mathrm{C}, \mathrm{L}, \mathrm{W}}^{10}$ & 35.9 & $1_{\mathrm{G}, \mathrm{Q}, \mathrm{W}}^{16, \mathrm{v}}$ & 1.3 & 65 & 17.7 \\
\hline Motivating & $11_{\mathrm{D}, \mathrm{H}}^{2, \mathrm{U}}$ & 9.9 & $13_{\mathrm{M}, \mathrm{R}}^{5}$ & 12.6 & $36_{\mathrm{D}, \mathrm{M}}^{11}$ & 46.2 & $42_{\mathrm{H}, \mathrm{R}}^{17}$ & 56.0 & 102 & 27.8 \\
\hline Questioning & $54_{\mathrm{A}, \mathrm{E}, \mathrm{I}}$ & 48.6 & $6_{\mathrm{A}, \mathrm{N}, \mathrm{S}}^{6}$ & 5.8 & $68_{\mathrm{E}, \mathrm{N}, \mathrm{X}}^{12}$ & 87.2 & $53_{\mathrm{I}, \mathrm{S}, \mathrm{X}}^{18, \mathrm{~N}}$ & 70.7 & 181 & 49.3 \\
\hline Differentiating & 7 & 6.3 & 8 & 7.8 & $0^{13}$ & .0 & 3 & 4.0 & 18 & 4.9 \\
\hline
\end{tabular}

Project Level

\begin{tabular}{|c|c|c|c|c|c|c|c|c|}
\hline Superscript & $z$ & $P$ & Superscript & $z$ & $P$ & Superscript & $z$ & $P$ \\
\hline 1 & 3.355 & .001 & 7 & 3.495 & $<10^{-3}$ & 13 & 2.257 & .024 \\
\hline 2 & 5.029 & $<10^{-6}$ & 8 & 6.165 & $<10^{-9}$ & 14 & 2.001 & .045 \\
\hline 3 & 2.604 & .009 & 9 & 2.052 & .040 & 15 & 4.649 & $<10^{-5}$ \\
\hline 4 & 2.221 & .026 & 10 & 4.735 & $<10^{-5}$ & 16 & 4.160 & $<10^{-4}$ \\
\hline 5 & 4.047 & $<10^{-4}$ & 11 & 4.074 & $<10^{-4}$ & 17 & 6.105 & $<10^{-8}$ \\
\hline 6 & 10.396 & $<10^{-25}$ & 12 & 7.527 & $<10^{-13}$ & 18 & 4.140 & $<10^{-4}$ \\
\hline \multicolumn{9}{|c|}{ Pair-Wise Level } \\
\hline Subscript & $z$ & $P$ & Subscript & $z$ & $P$ & Subscript & $z$ & $P$ \\
\hline $\mathrm{A}$ & 6.95 & $<10^{-11}$ & I & 2.97 & .003 & $\mathrm{R}$ & 6.17 & $<10^{-9}$ \\
\hline B & 5.73 & $<10^{-8}$ & $\mathrm{~J}$ & 3.71 & $<10^{-3}$ & $\mathrm{~S}$ & 9.05 & $<10^{-18}$ \\
\hline $\mathrm{C}$ & 2.46 & .014 & $\mathrm{~K}$ & 5.81 & $<10^{-8}$ & $\mathrm{~T}$ & 3.06 & .002 \\
\hline D & 5.66 & $<10^{-7}$ & $\mathrm{~L}$ & 3.51 & $<10^{-3}$ & $\mathrm{U}$ & 5.54 & $<10^{-7}$ \\
\hline $\mathrm{E}$ & 5.44 & $<10^{-7}$ & M & 5.01 & $<10^{-6}$ & $\mathrm{~V}$ & 3.92 & $<10^{-4}$ \\
\hline $\mathrm{F}$ & 4.99 & $<10^{-6}$ & $\mathrm{~N}$ & 10.99 & $<10^{-27}$ & $\mathrm{~W}$ & 5.44 & $<10^{-7}$ \\
\hline $\mathrm{G}$ & 3.75 & $<10^{-3}$ & $\mathrm{P}$ & 2.95 & .003 & $\mathrm{X}$ & 2.50 & .012 \\
\hline $\mathrm{H}$ & 6.81 & $<10^{-11}$ & $Q$ & 2.90 & .004 & & & \\
\hline
\end{tabular}

Note. - Number and overall percentage of the episodes coded for each didactic strategy in each country. Numerical superscripts refer to significant project-level differences, as identified by Mann-Whitney $U$-tests, where each country's data are compared with those derived from all other countries. Alphabetic subscripts refer to significant pair-wise differences, where each country's data are compared with those from each other country.

coaching and motivating than in Spain. Additionally, Hungarian episodes attracted significantly higher proportions of activating, sharing, assessing, and questioning but a lower proportion of coaching than did Spanish episodes.

\section{A Second-Level Analysis}

In the following part, we show how the project's strategies facilitate the inference of didactically complex activity. In so doing, we draw explicitly on the fact that most episodes were multiply coded. Space prevents a complete presentation of this secondary analysis but, in brief, it entailed what follows. Whenever an episode was coded for one strategy, say explaining, the record for that episode was checked for each of the remaining strategies. This process allowed us to count the number of episodes coded for explaining with 
activating, explaining with exercising, explaining with sharing, and so on. In this way we were able to examine some of the interactions between the didactic strategies in simple-to-report, accessible ways.

Table 4 shows the frequencies of episodes coded for explaining with each other strategy except for exercising, exploring, and differentiating, due to their effective absences. In terms of commonalities, it can be seen that when they explain, project teachers tend to share regularly, although not necessarily in similar proportions. Project teachers also appear to coach when explaining - around a third of Flemish, half of English and Hungarian, and threequarters of Spanish episodes coded for explaining also included coaching. We believe that this indicates frequent but variable emphases on procedural rather than conceptual learning outcomes.

At the project level, represented by alphabetic subscripts in table 4 , the proportions of Flemish episodes coded for explaining with coaching and explaining with motivating were significantly smaller than the totality of all other episodes. The proportions of English lessons coded for explaining with motivating and explaining with questioning were smaller than elsewhere. For Hungarian episodes, the proportions coded for explaining with activating, sharing, assessing, and questioning were all larger than elsewhere. Finally, the proportions of Spanish episodes coded for explaining with sharing and explaining with assessing were smaller than elsewhere, while the proportions coded for explaining with coaching and explaining with motivating were larger than elsewhere.

At the pair-wise level, represented by numerical superscripts in table 4, it can be seen that English and Spanish episodes comprise a significantly lower proportion of episodes coded for explaining with activating than do Hungarian episodes. Hungarian teachers shared in all but one of that country's 46 episodes coded for explaining, something that sets them apart from colleagues in other countries. Hungarian episodes coded for explaining also incorporated higher proportions of assessing than did Flemish or Spanish episodes and higher proportions of questioning than did those of any other country. Spanish episodes coded for explaining incorporated higher proportions of motivating than did English or Flemish episodes and higher proportions of coaching than did those of any other country. Flemish episodes coded for explaining comprised a higher proportion of questioning than did English episodes.

\section{Construct Validation}

Our approach to construct validation is to assess the extent to which the outcomes yielded by our instrument resonate with those derived from other forms of project data (triangulation) and earlier studies. Thus, summaries of each country's mathematics teaching traditions, drawn from the available literature, are supplemented by brief cameos drawn from an early lesson on 
TABLE 4

Secondary Analyses of Episodes Coded for Explaining

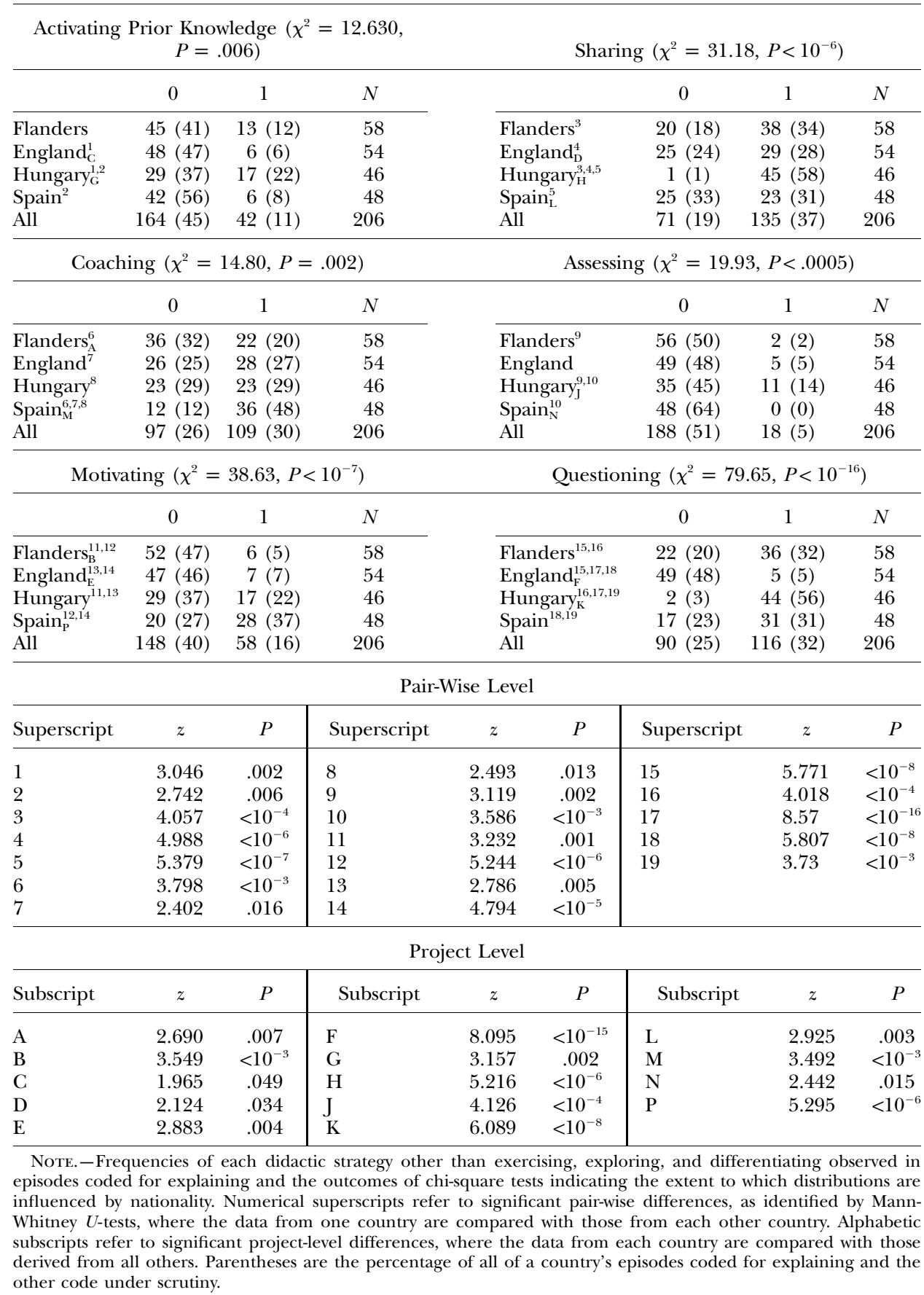


linear equations recorded in that country. To frame our discussion further, we introduce three concepts that emerged from our analyses and that facilitate description and comparison. The first, didactic complexity, refers to the extent to which episodes are multiply coded. The second, didactic coherence, refers to the quality of the interactions between strategies. For example, a regular juxtaposition of exploring and exercising-something never seen in project lessons-would be construed as low in didactic coherence because the objectives of the two strategies are essentially incompatible. The third, didactic ambition, refers to the learning objectives inferable from the strategies. For example, an emphasis on procedural knowledge can be inferred from a concurrent emphasis on explaining and coaching.

Flanders.-The mean Flemish lesson duration, episode duration, and episodes per lesson were commensurate with project norms. There were significantly fewer codes per episode than elsewhere, however, which is indicative of a limited didactic complexity. The dominant mode of interaction observed was whole class, although both individual working and paired activity were not uncommon.

Sharing was the most frequently observed strategy in accordance with the regularity of whole-class work. Both explaining and questioning were observed in half of all episodes, indicative of a privileging of teacher and student voices, although not simultaneously. Motivating was rare, and coaching was significantly less common than elsewhere, indicating that Flemish teachers offer less explicit support to learners' routine work than do teachers in the other countries under study. This conjecture is supported by evidence from a lesson on linear equations during which the teacher explained, with much questioning, the solution of an introductory equation that included brackets and the unknown on both sides. The episode, which included the activation of concepts such as commutativity, associativity, and distributivity, showed an emphasis on nontrivial procedures linked to generalized forms of equation and confirmed that Flemish teachers emphasize not only the vocabulary of mathematics but also its syntax and structure (Szeredi and Török 2005). In such circumstances it is possible that students are given such precise instructions that further motivational interventions are unnecessary. The totality of the above tends to indicate, at the very least, moderate didactic ambition.

Flemish episodes exhibited, at project norm levels, both activating and assessing. The former indicates that the learning experience of Flemish students is largely coherent-as in the revisiting of earlier material during the equation-solving example above-while the latter alludes to a didactic flexibility whereby teachers adapt their lessons in the light of feedback. The regular occurrences of sharing and explaining allude to a public discourse that, while largely teacher controlled, is not independent of expectations of the higher-order thinking associated with questioning. It may also explain 
internal commentators' concerns that Flemish mathematics teaching is largely transmissive (Waeytens et al. 1997) and privileges declarative knowledge and lower-order procedural skills (Janssen et al. 2002) above those of problem solving (Verschaffel et al. 1997; Yoshida et al. 1997). This conjecture is supported by the fact that the equation discussed above was presented independently of any context.

The second-level analysis indicates that when Flemish teachers explain, they also share and question, as in the equations lesson above. Moreover, half of all episodes coded for activating and coaching occurred during episodes also coded for explaining, indicating emphases on both cognitive and behavioral outcomes. None of these juxtapositions could be construed as incompatible and, when considered with the above, allude to a tradition of limited didactic complexity, moderate didactic ambition, and moderately high didactic coherence.

England.-The mean English lesson duration was commensurate with project norms, although the English lessons incorporated significantly more, but significantly shorter, episodes than elsewhere. Also, the mean number of codes per episode was significantly smaller than the norm, indicating a limited didactic complexity. The dominant mode of interaction was the whole class, although both individual work and group activity were not uncommon. This finding, viewed alongside the higher than average number of episodes per English lesson, accords with earlier studies highlighting frequent, but short, periods of whole-class discussion (Leung 1995; Wilson et al. 2001; Kaiser et al. 2006).

With the exception of exercising, English teachers did not exploit any strategy in frequencies higher than elsewhere. The frequency of sharing confirms whole-class activity as a regular classroom feature, while regular coaching and explaining, together with the almost complete absence of questioning, indicate an emphasis on procedural skills (in line with Pepin 1998; Pepin and Moon 1999; Kaiser 2002) and a rare emphasis on higher-order thinking. This absence of questioning resonates with findings that wholeclass interactions are typified by "a series of short, closed questions, maximizing the number of pupils required to provide oral responses" (Wilson et al. 2006, 430). Frequent instances of coaching may explain the low levels of motivating and assessing, particularly in a discourse of low cognitive demand.

The second-level analysis found that when English teachers explain, they share and coach in roughly equal measures, with little evidence of other strategies. These findings signal a low level of didactic complexity, infrequent pursuit of higher-order outcomes, and a dominance of teacher-directed procedural acquisition. And in teaching linear equations, the English teacher, having spent three lessons rehearsing various skills of algebraic manipulation, publicly explained and coached her students through the solutions of several linear equations with the unknown on one side, equations that students would 
have been able to solve mentally by a process of undoing. Such pedagogical behavior finds resonance not only with Birgit Pepin and Bob Moon's (1999) observation that English teachers explain concepts or skills by means of examples worked on the board but also with Sue Jennings and Richard Dunne's (1996) observation that English teachers, when compared to their French colleagues, privilege procedural skills and simplify mathematics rather than engage their learners in the complexity of the subject. The totality warrants a conjecture that the English episodes, with their frequent stress on procedural skills but rare emphasis on higher-order thinking, comprise not only relatively high levels of didactic coherence, in that the strategies employed are commensurate with the inferred low-level outcomes, but relatively low levels of didactic ambition.

Hungary.-The mean Hungarian lesson duration was significantly shorter, the average number of episodes per lesson was significantly smaller, and the mean episode duration was commensurate with project norms. Also, Hungary's number of codes per episode was significantly higher than the project norm, indicative of high didactic complexity. Every Hungarian episode involved some whole-class activity with more than two-fifths also incorporating individual work. Paired work and group work were essentially absent. Thus, guaranteed whole-class activity within $10 \mathrm{~min}$. episodes confirms that extended periods of seat work are rare (Graham et al. 1999; Andrews 2003).

The high proportions of sharing and questioning indicate a public and high-level discourse, which, according to Andrews (2003) and Julianna Szendrei (2007), is likely to revolve around solutions to nonroutine problems. The higher-than-elsewhere levels of activating suggest that Hungarian teachers frequently make links to other topics (Andrews 2003). The regularity of seat work, within episodes comprising whole-class activity, suggests, in the manner described by Andrews (2003), that problems are generally solved one at a time, as indicated by the regularity of assessing, with teachers constantly monitoring students' comprehension to determine future actions (Graham et al. 1999). Moreover, an implicit expectation that student difficulties will find resolution through the public discourse may explain the relative lack of coaching. Finally, Hungarian teachers motivate regularly, which may be a consequence of a discourse dominated by little explicit telling or demonstrating of rules or procedures.

The second-level analysis showed that when Hungarian teachers explain, they also share and question. Thus, within an episode, teacher explanation is complemented by student contributions and responses to higher-order questions. The analysis also shows that when they explain they frequently coach and, occasionally, motivate, activate, and assess. This suggests that procedural issues are not subordinated to cognitive.

The above-described didactic coherence and didactic ambition were highlighted by an equations lesson in which the teacher presented a word problem 
concerning the delivery of potatoes to the school's kitchen. Students interacting with the teacher constructed an equation, with the unknown on both sides, before solving it publicly. This involved the teacher's drawing a scale balance with bags of potatoes in the two scale pans and a number of students offering various suggestions. Such practices accord closely with earlier observations that Hungarian teachers regularly use manipulatives or drawings to scaffold students' learning (Graham et al. 1999; Andrews 2003). Moreover, there is little in the above to suggest that the didactics observed in the Hungarian episodes "deviated from the . . . cycle of problem posing, solving and sharing pattern of activity" (Andrews 2003, 219), a pattern also observed earlier (Szalontai 2000). Thus, we argue that the evidence supports a conjecture that Hungarian episodes comprised high levels of didactic ambition, didactic complexity, and didactic coherence.

Spain.-The mean Spanish lesson and episode durations were significantly longer than the norm. The mean episodes per lesson was commensurate with project norms, while the number of codes per episode was significantly higher, indicative of moderate to high didactic complexity. Almost every Spanish episode involved whole-class activity with almost two-fifths also incorporating individual work. There was occasional paired work, but group work was essentially absent.

Coaching and questioning were seen in such high proportions that at least half of all Spanish episodes comprised both. Frequent coaching may indicate an emphasis on procedural goals, a conjecture supported by Fien Depaepe et al.'s (2005) description of Spanish lessons and William Schmidt et al.'s (1996) observation that Spanish teachers frequently circulate within the classroom, helping individuals. In general, simultaneous questioning would challenge this interpretation and indicate an emphasis on adaptive expertise, or the flexible, efficient, effective, and creative application of content knowledge (in line with Baroody and Dowker 2003). Depaepe et al.'s (2005) study found little evidence of this theory, however. The frequency of sharing confirms not only the regularity of whole-class activity but also, as evidenced by the regularity of questioning, the acknowledgment of the student's voice alongside that of the teacher's. In summary, the Spanish teachers exploited five strategies in high proportions, but the coherence of their actions was not always apparent, in accordance with Lorenzo Blanco's (2003) observation that Spanish teachers have idiosyncratic views about mathematics teaching.

The second-level analysis found that around half the episodes coded for explaining were also coded for either sharing or motivating. These proportions rose to three-quarters and two-thirds, respectively, for episodes coded for explaining with coaching and explaining with questioning. The juxtaposition of these two results shows that at least half of all Spanish episodes comprised explaining, questioning, and coaching simultaneously. Such pro- 
portions not only further support the findings above but also, particularly when set against the regularity of motivating, indicate that learning in Spanish classrooms "is directly proportional to the capacity to manage the class and to the skill in creating and sustaining a productive discourse in the classroom" (Blanco 2003, 6). When viewed as a whole, the above findings indicate that the Spanish episodes exhibited moderately high didactic complexity with a moderate didactic ambition undermined by low levels of didactic consistency.

The introductory Spanish lesson on equations exemplifies well this idiosyncratic pattern. Having encouraged his students to attempt trial and improvement solutions to $x^{2}-2=0$, a nonroutine and challenging question, the teacher explained the solution process for $100-n=0$. In other words, having engaged students in an episode of higher-order thinking, he modeled the formal solution process of an equation his students could solve mentally; this episode offers an illustration of the didactic confusion noted earlier (see Planas and Gorgorió 2004).

\section{Closing Remarks}

The samples on which this article is based are small with limited representativeness, albeit mediated by local criteria of effective practice, and potential for generalization. The focus of the article has not been, however, to construct generalities but to demonstrate the validity and research potential of the instrument (and coding procedures). To accomplish this task, we have presented exemplary analyses in ways we hope will avoid charges of unwarranted speculation (Jenkins 2000).

Furthermore, we have shown resonance between our findings and those of the available literature and qualitative summaries of specific project lessons. Project data show that seven of the 10 generic didactic strategies were sufficiently narrow as to expose meaningful didactic differences between the teachers of the four countries but sufficiently broad as to highlight important similarities. Importantly, by way of further warranting the power of generic codes in comparative education research, we return to explaining as the vehicle in which this particular journey was undertaken. We discussed, in relation to some of the available literature, various forms of explaining but persisted with a broad and inclusive definition. This approach could have been construed as a risky strategy, as other studies in which broad and inclusive variables were examined tended to find little discrimination between their units of comparison (LeTendre et al. 2001). As we had expected, however, the juxtaposition of this broadly defined construct with other broadly defined constructs reflects well various forms of explaining and facilitates discrimination between the practices of teachers in project countries.

In addition to providing evidence of construct validity, we need to consider issues of reliability. In this regard, we note that project colleagues, irrespective of their country of origin, were able to agree on not only the 
entry and exit points of lesson episodes but also the didactic strategies observed within them. This outcome, following the difficulty experienced during the first year of the project, was satisfactory and suggests that the descriptors of both generic episodes and generic codes were reasonably straightforward to operationalize. Indeed, we believe that the reliability of the instrument was enhanced because of the inductive and grounded manner in which it was developed, with every colleague later involved in the coding process also involved, at some time during the first year, in the collaborative observations and discussions underpinning the instrument's development.

Thus, our view is that a modified instrument has the potential to make a worthwhile and important contribution to comparative education research in general and the debate concerning the national teaching script in particular. The exemplary analyses have confirmed the power of generic codes in comparative work and shown how the interactions of the various didactic strategies create constellations of activity that, through their distinctive characteristics, contribute powerfully to the national teaching scripts debate.

Interestingly, much comparative mathematics education research has, essentially, presented the national teaching script as a temporal construct, defined more by when teachers do things than by what they do. Our data indicate that it can just as easily be construed as an emphatic construct, defined as much by what teachers do as by when they do it. However, when considered in this manner, any temporality embedded in a repeatedly enacted script or characteristic pedagogical flow is lost. Therefore, we argue that Paul Cobb et al.'s (1992) traditions metaphor may be a more appropriate description of the constellations of activity found in the classrooms of project teachers.

Finally, a complete account of teachers' actions necessitates our understanding why teachers do what they do, and this, we argue, requires complementary research that goes beyond the sort of quantification presented here. Generic codes can tell us, in ways that allow for meaningful comparison, what is happening in a country's classrooms but offer little in terms of explaining why it happens. Therefore, attention should be paid not only to sociocultural and historicopolitical analyses of educational systems and traditions but also to studies that privilege the voice of individuals, as in the case of Andrews's (2007a) study of English and Hungarian teachers' beliefs about the nature of mathematics and its privileged curricular place. ${ }^{5}$ In this way description can be supplemented by explanation and, ultimately, theory.

\footnotetext{
${ }^{5}$ On sociocultural and historicopolitical analyses of educational systems and traditions, see, e.g., Hofstede (1986, 2001), Holmes and McLean (1989), Hess and Azuma (1991), McLean (1995), and Cummings (1999, 2003).
} 


\section{References}

$\rightarrow$ Aguirre, Julia, and Natasha Speer. 2000. "Examining the Relationship between Beliefs and Goals in Teacher Practice.” Journal of Mathematical Behavior 18 (3): 327-56.

Alexander, Robin. 1999. "Culture in Pedagogy: Pedagogy across Cultures." In Contexts, Classrooms, and Outcomes. Vol. 1 of Learning from Comparing, ed. Robin Alexander, Patricia Broadfoot, and David Phillips. Oxford: Symposium.

$\rightarrow$ Andrews, Paul. 2003. "Opportunities to Learn in the Budapest Mathematics Classroom." International Journal of Science and Mathematics Education 1 (2): 201-25.

$\rightarrow$ Andrews, Paul. 2007a. "The Curricular Importance of Mathematics: A Comparison of English and Hungarian Teachers' Espoused Beliefs." Journal of Curriculum Studies 39 (3): 317-38.

$\rightarrow$ Andrews, Paul. 2007b. "Negotiating Meaning in Cross-National Studies of Mathematics Teaching: Kissing Frogs to Find Princes." Comparative Education 43 (4): 489-509.

Baroody, Arthur, and Ann Dowker, eds. 2003. The Development of Arithmetic Concepts and Skills: Constructing Adaptive Expertise. Mahwah, NJ: Erlbaum.

Beaton, Albert E., Ina Mullis, Michael Martin, Eugenio Gonzalez, Dana Kelly, and Teresa Smith. 1996. Mathematics in the Middle School Years: IEA's Third International Mathematics and Science Study (TIMSS). Boston: Boston College Press.

Blanco, Lorenzo. 2003. "The Mathematical Education of Primary Teachers in Spain." International Journal of Mathematics Teaching and Learning (April). http:/ / www.cimt.plymouth.ac.uk/journal/blancol.pdf.

$\rightarrow$ Borko, Hilda. 2004. "Professional Development and Teacher Learning: Mapping the Terrain." Educational Researcher 33 (8): 3-15.

$\rightarrow$ Borko, Hilda, and Carol Livingston. 1989. "Cognition and Improvisation: Differences in Mathematics Instruction by Expert and Novice." American Educational Research Journal 26 (4): 473-98.

Clarke, David. 2006. “The LPS Research Design.” In Mathematics Classrooms in Twelve Countries: The Insider's Perspective, ed. David Clarke, Christine Keitel, and Yoshinori Shimizu. Rotterdam: Sense.

Clarke, David, Jonas Emanuelsson, Eva Jablonka, and Ida Mok, eds. 2006. Making Connections: Comparing Mathematics Classrooms around the World. Rotterdam: Sense.

Clarke, David, Christine Keitel, and Yoshinori Shimizu, eds. 2006. Mathematics Classrooms in Twelve Countries: The Insider's Perspective. Rotterdam: Sense.

Clarke, David, Carmel Mesiti, Eva Jablonka, and Yoshinori Shimizu. 2006. "Addressing the Challenge of Legitimate International Comparisons: Lesson Structures in the USA, Germany, and Japan." In Making Connections: Comparing Mathematics Classrooms around the World, ed. David Clarke, Jonas Emanuelsson, Eva Jablonka, and Ida Mok. Rotterdam: Sense.

$\rightarrow$ Cobb, Paul, Terry Wood, Erna Yackel, and Betsy McNeal. 1992. "Characteristics of Classroom Mathematics Traditions: An Interactional Analysis.” American Educational Research Journal 29 (3): 573-604.

$\rightarrow$ Cummings, Walter. 1999. "The Institutions of Education: Compare, Compare, Compare!" Comparative Education Review 43 (4): 413-37. 
ANDREWS

Cummings, Walter. 2003. The InstitutionS of Education: A Comparative Study of Educational Development in the Six Core Nations. Oxford: Symposium.

$\rightarrow$ Davis, Brent, and Elaine Simmt. 2006. "Mathematics-for-Teaching: An Ongoing Investigation of the Mathematics That Teachers (Need to) Know." Educational Studies in Mathematics 61 (3): 293-319.

Depaepe, Fien, Erik De Corte, Peter Op't Eynde, and Lieven Verschaffel. 2005. "Teaching Percentages in the Primary School: A Four Country Comparative Study." In Powerful Environments for Promoting Deep Conceptual and Strategic Learning, ed. Lieven Verschaffel, Erik Corte, Gellof Kanselaar, and Martin Valcke. Leuven: Leuven University Press.

$\rightarrow$ Graham, Ted, Stuart Rowlands, Sue Jennings, and John English. 1999. "Towards Whole-Class Interactive Teaching." Teaching Mathematics and Its Applications 18 (2): 50-60.

$\rightarrow$ Hess, Robert, and Hiroshi Azuma. 1991. "Cultural Support for Schooling: Contrasts between Japan and the United States." Educational Researcher 20 (9): 2-8.

Hiebert, James. 1986. Conceptual and Procedural Knowledge: The Case of Mathematics. Hillsdale, NJ: Erlbaum.

Hiebert, James, Ronald Gallimore, Helen Garnier, Karen Bogard Givvin, Hilary Hollingsworth, Jennifer Jacobs, Angel Miu-Ying Chui, Diane Wearne, Margaret Smith, Nicole Kerstling, Alfred Manaster, Ellen Tseng, Wallace Etterbeek, Carl Manaster, Patrick Gonzales, and James Stigler. 2003. Teaching Mathematics in Seven Countries: Results from the TIMSS 1999 Video Study. Washington, DC: National Center for Educational Statistics.

$\rightarrow$ Hofstede, Geert. 1986. "Cultural Differences in Teaching and Learning." International Journal of Intercultural Relations 10 (3): 301-20.

Hofstede, Geert. 2001. Culture's Consequences: Comparing Values, Behaviors, Institutions, and Organizations across Nations. 2nd ed. London: Sage.

Holmes, Brian, and Martin McLean. 1989. The Curriculum: A Comparative Perspective. London: Hyman.

$\rightarrow$ Hufton, Neil, and Julian Elliott. 2000. "Motivation to Learn: The Pedagogical Nexus in the Russian School; Some Implications for Transnational Research and Policy Borrowing." Educational Studies 26 (1): 115-36.

$\rightarrow$ Inoue, Noriyuki. 2009. "Rehearsing to Teach: Content-Specific Deconstruction of Instructional Explanations in Preservice Teacher Training." Journal of Education for Teaching 35 (1): 47-60.

$\rightarrow$ Janssen, Rianne, Erik De Corte, Lieven Verschaffel, Evelyn Knoors, and Ariane Colemont. 2002. "National Assessment of New Standards for Mathematics in Elementary Education in Flanders." Educational Research and Evaluation 8 (2): 197-225.

Jenkins, Edgar. 2000. "Making Use of International Comparisons of Student Achievement in Science and Mathematics." In Learning from Others, ed. Diane Shorrocks-Taylor and Edward Jenkins. Dordrecht: Kluwer.

$\rightarrow$ Jennings, Sue, and Richard Dunne. 1996. "A Critical Appraisal of the National Curriculum by Comparison with the French Experience." Teaching Mathematics and Its Applications 15 (2): 49-55.

$\rightarrow$ Kaiser, Gabriele. 2002. "Educational Philosophies and Their Influence on Math- 
ematics Education: An Ethnographic Study in English and German Mathematics Classrooms." Zentralblatt für Didaktik der Mathematik 34 (6): 241-57.

Kaiser, Gabriele, Keiko Hino, and Christine Knipping. 2006. "Proposal for a Framework to Analyse Mathematics Education Traditions in Eastern and Western Traditions." In Mathematics Education in Different Cultural Traditions: A Comparative Study of East Asia and the West; The 13th ICMI Study, ed. Frederick K. S. Leung, Klaus-D. Graf, and Francis J. Lopez-Real. New York: Springer.

Kawanaka, Takako, James Stigler, and James Hiebert. 1999. "Studying Mathematics Classrooms in Germany, Japan, and the United States: Lessons from the TIMSS Videotape Study." In International Comparisons in Mathematics Education, ed. Gabriele Kaiser, Eduardo Luna, and Ian Huntley. London: Falmer.

Kilpatrick, Jeremy, Jane Swafford, and Bradford Findell, eds. 2001. Adding It Up: Helping Children Learn Mathematics. Washington, DC: National Academies.

$\rightarrow$ King, Alison. 1994. "Guiding Knowledge Construction in the Classroom: Effects of Teaching Children How to Question and How to Explain." American Educational Research Journal 31 (2): 338-68.

$\rightarrow$ Knipping, Christine. 2003. "Learning from Comparing: A Review and Reflection on Qualitative Oriented Comparisons of Teaching and Learning Mathematics in Different Countries.” Zentralblatt für Didaktik der Mathematik 35 (6): 282-93.

$\rightarrow$ Knoll, Steffen, and James Stigler. 1999. "Management and Analysis of Large-Scale Video Surveys Using the Software vPrism." International Journal of Educational Research 31 (8): 725-34.

Leinhardt, Gaea. 2001. "Instructional Explanations: A Commonplace for Teaching and Location for Contrast." In Handbook of Research on Teaching, ed. Virginia Richardson. 4th ed. Washington, DC: American Educational Research Association.

$\rightarrow$ Leinhardt, Gaea, and Michael Steele. 2005. "Seeing the Complexity of Standing to the Side: Instructional Dialogues." Cognition and Instruction 23 (1): 87-163.

$\rightarrow$ LeTendre, Gerald, David Baker, Motoko Akiba, Brian Goesling, and Alexander Wiseman. 2001. "Teachers' Work: Institutional Isomorphism and Cultural Variation in the U.S., Germany, and Japan.” Educational Researcher 30 (6): 3-15.

$\rightarrow$ Leung, Frederick. 1995. "The Mathematics Classroom in Beijing, Hong Kong, and London." Educational Studies in Mathematics 29 (4): 297-325.

McLean, Martin. 1995. "The European Union and the Curriculum." Oxford Studies in Comparative Education 5 (2): 29-46.

Mullis, Ina, Michael Martin, and Pierre Foy. 2008. TIMSS 2007 International Mathematics Report: Findings from IEA's Trends in International Mathematics and Science Study at the Fourth and Eighth Grades. Boston: Boston College Press.

Mullis, Ina, Michael Martin, Eugenio Gonzalez, and Steven Chrostowski. 2004. TIMSS 2003 International Mathematics Report. Boston: Boston College Press.

Mullis, Ina, Michael Martin, Eugenio Gonzalez, Kelvin Gregory, Robert Garden, Kathleen O'Connor, Steven Chrostowski, and Teresa Smith. 2000. TIMSS 1999 International Mathematics Report. Boston: Boston College Press.

OECD (Organization for Economic Cooperation and Development). 2001. Knowledge and Skills for Life: First Results from the OECD Programme for International Student Assessment (PISA) 2000. Paris: OECD.

OECD (Organization for Economic Cooperation and Development). 2004. Learning for Tomorrow's World: First Results from PISA 2003. Paris: OECD. 
Pepin, Birgit. 1998. "Curriculum, Cultural Traditions, and Pedagogy: Understanding the Work of Teachers in England, France, and Germany." Paper presented at the European Conference for Educational Research, Ljubljana.

Pepin, Birgit, and Bob Moon. 1999. "Curriculum, Cultural Traditions, and Pedagogy: Understanding the Work of Teachers in England, France, and Germany." Paper presented at the annual meeting of the American Educational Research Association, Quebec.

Planas, Nuria, and Nuria Gorgorió. 2004. "Are Different Students Expected to Learn Norms Differently in the Mathematics Classroom?" Mathematics Education Research Journal 16 (1): 19-40.

$\rightarrow$ Roscoe, Rod D., and Michelene T. H. Chi. 2008. "Tutor Learning: The Role of Explaining and Responding to Questions.” Instructional Science 36 (4): 321-50.

Schmidt, William, Doris Jorde, Leland Cogan, Emilie Barrier, Ignacio Gonzalo, Urs Moser, Katsuhiko Shimizu, Toshio Sawada, Gilbert Valverde, Curtis McKnight, Richard Prawat, David Wiley, Senta Raizen, Edward Britton, and Richard Wolfe. 1996. Characterizing Pedagogical Flow: An Investigation of Mathematics and Science Teaching in Six Countries. Dordrecht: Kluwer.

Stigler, James, Patrick Gonzales, Takako Kawanaka, Steffen Knoll, and Ana Serrano. 1999. The TIMSS Videotape Classroom Study. Washington, DC: National Center for Educational Statistics.

Stigler, James, and James Hiebert. 1999. The Teaching Gap. New York: Free Press.

Stodolsky, Susan. 1988. The Subject Matters: Classroom Activity in Math and Social Studies. Chicago: University of Chicago Press.

Szalontai, Tibor. 2000. "Some Facts and Tendencies in Hungarian Mathematics Teaching." International Journal of Mathematics Teaching and Learning, June. http:// www.cimt.plymouth.ac.uk/journal/tshungmt.pdf.

$\rightarrow$ Szendrei, Julianna. 2007. "When the Going Gets Tough, the Tough Gets Going: Problem Solving in Hungary, 1970-2007; Research and Theory, Practice and Politics." Zentralblatt für Didaktik der Mathematik 39 (5-6): 443-58.

Szeredi, Eva, and Judit Török. 2005. "Teaching Polygons in the Secondary School: A Four Country Comparative Study." Paper presented to the biennial conference of the European Association for Research into Learning and Instruction, Nicosia.

Ulewicz, Monica, and Alexandra Beatty, eds. 2001. The Power of Video Technology in International Comparative Research in Education. Washington, DC: National Academies.

$\rightarrow$ Verschaffel, Lieven, Erik De Corte, and Inge Borghart. 1997. "Pre-service Teachers Conceptions and Beliefs about the Role of Real-World Knowledge in Mathematical Modelling of School Word Problems." Learning and Instruction 7 (4): 339-59.

Waeytens, Kim, Willy Lens, and Roland Vandenberghe. 1997. "Learning to Learn: How Do Teachers Differ?" Paper presented at the annual meeting of the American Educational Research Association, Chicago.

$\rightarrow$ Wilson, Linda, Carolyn Andrew, and John Below. 2006. "A Comparison of Teacher/ Pupil Interaction within Mathematics Lessons in St. Petersburg, Russia, and the North-East of England.” British Educational Research Journal 32 (3): 411-41.

$\rightarrow$ Wilson, Linda, Carolyn Andrew, and Svetlana Sourikova. 2001. "Shape and Structure in Primary Mathematics Lessons: A Comparative Study in the North-East of 
England and St. Petersburg, Russia; Some Implications for the Daily Mathematics Lesson.” British Educational Research Journal 27 (1): 30-58.

$\rightarrow$ Yoshida, Hajime, Lieven Verschaffel, and Erik De Corte. 1997. "Realistic Considerations in Solving Problematic Word Problems: Do Japanese and Belgian Children Have the Same Difficulties?” Learning and Instruction 7 (4): 329-38. 